\title{
SYNOPSIS OF OPERATIONAL RESEARCH IN THE UK MINISTRY OF DEFENCE
}

\author{
Roger FORDER
}

The Defence Science and Technology Laboratory (Dstl) is an Executive Agency of the UK Ministry of Defence (MoD). Dstl is 'owned' by the Minister for Defence Equipment and Support.

Dstl was formed in 2001 when $75 \%$ of the Defence Evaluation and Research Agency was reconstituted as a Government-owned company (QinetiQ) in preparation for privatization. Dstl retained within MoD to undertake defence $S \& T$ work that would be inappropriate for the private sector. The staff of the laboratory totals 3500 people (including 100 military).

Dstl operates as a Government Trading Fund (i.e. $100 \%$ 'contract' funded), owned by the Secretary of State for Defence.

It undertakes work for almost every part of $\mathrm{MoD}$ and a number of other UK Government departments and agencies.

\section{Dstl's Role}

The stated purpose of Dstl is to deliver value to the UK taxpayer by providing outputs of research, timely advice and solutions to customers' defence and security-related problems. Its stated mission is "to create the winning edge for UK Forces and Government through the best use of Science and Technology." Its stated vision is "to be the indispensable source of Science and Technology at the heart of defence."

The role of Dstl could be summarized as follows:

- In-house analysis and systems assessment advice, to support defence policy, defence programme and weapon systems acquisition decisions

- Science and technology support to operations (including analysis)

- Research 
○ in particularly sensitive areas

- or where deep understanding needed for defence purposes

- Knowledge integration

- based on global science and technology

- Focus for international research collaboration

$\circ$ government to government

- Dstl does not undertake commercial contracts unless directed to do so by MoD.

\section{Operational Analysis in Dstl}

Dstl carries out most of the Operational Analysis (OA) for the UK MoD. About 300 of Dstl's 3500 staff are engaged on OA or closely related activities:

- $20 \%$ on policy and force structure issues

- $60 \%$ on acquisition issues

- $20 \%$ in support of frontline operations.

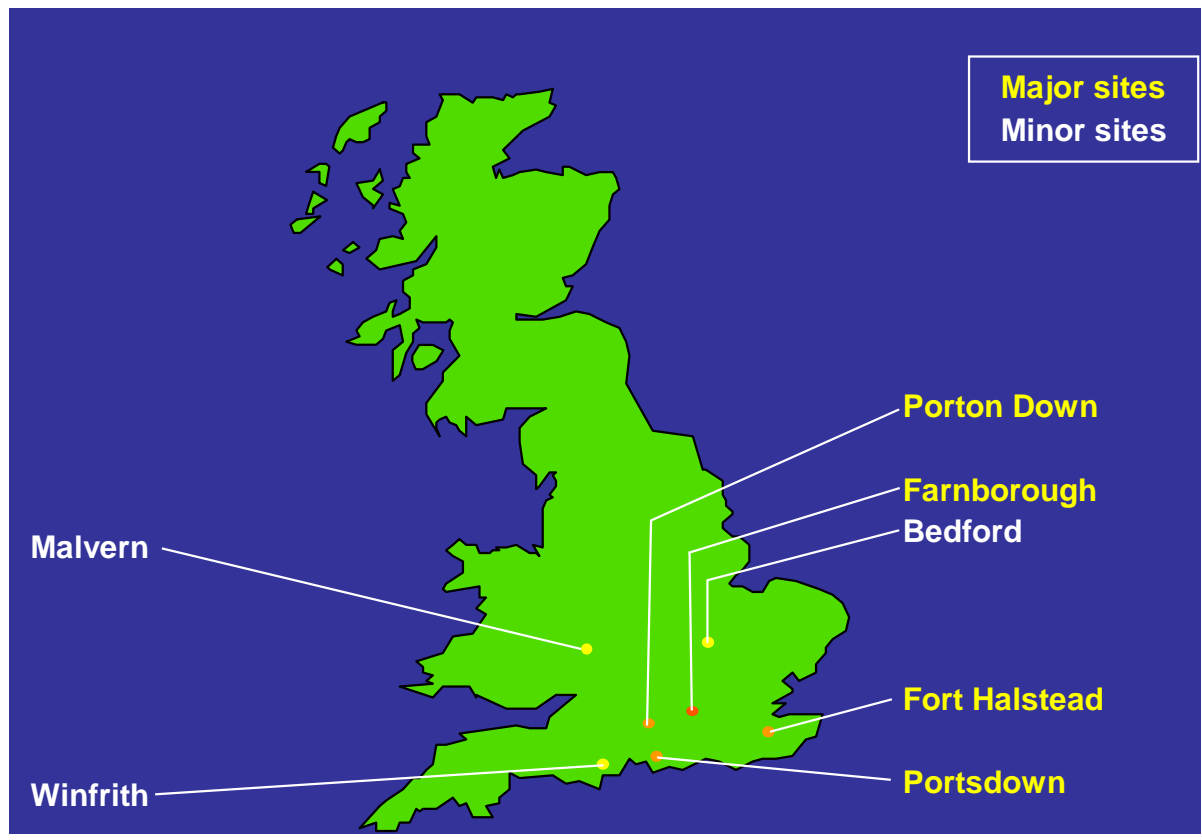

Figure 1: Locations of Dstl. 


\section{Policy \& Capability}

Studies

Naval Systems
Land Battlespace

Systems
Joint Systems

Air and Weapons

Systems
Information

Management

\section{Systems engineering and analysis}

Energetics

Electronics
Sensors and Countermeasures

Detection

Biomedical

Sciences
Physical

Sciences
Environmental Sciences

\section{Critical defence science and technology}

Figure 2: Departments of Dstl.

Major MoD customers for $\mathrm{OA}$ are:

- Policy Director

- Deputy Chief of Defence Staff (Equipment Capability)

- Science and Technology Director

- Defence Equipment and Support (MoD's new unified materiel acquisition and support organization)

- Operational commands and headquarters.

The academic backgrounds of the OA staff can be grouped as follows:

- Mathematics

- Operational research

- Computer science

- Physical sciences

- Psychology

- Anthropology

- War studies / international relations.

\section{Locations and Organisation of Dstl}

Figure 1 illustrates the locations of Dstl. 
Dstl departments are depicted in Figure 2. Nearly all OA work is performed in the following departments: Policy \& Capability Studies, Joint Systems, Naval Systems, Land Battlespace Systems, and Air and Weapons Systems.

\section{Links with Defence OA / OR and the Broader OR Community}

Dstl participates in the NATO System Analysis and Studies Panel, and the activities under the panel, as important part of its international collaboration. Of great benefit are also multilateral and bilateral links with Australia, Canada, France, the Netherlands, New Zealand, Norway, Sweden and the United States. The cooperation within the framework of ISMOR (International Symposium on Military OR), held annually in UK, has to be mentioned in this respect, too.

Dstl's participation in the broader international OR community (trough conferences, workshops, etc) is also valuable. Dstl participates in the Operational Research Society - the UK's national society for OR practitioners and academics, with about 2700 members, that offers accredited membership categories (Fellow, Associate Fellow, etc.).

Dstl collaborates also with various university departments of operational research and management science and OR groups in civil departments of UK Government. The conferences attended by Dstl's staff are the annual conference of the OR Society, the conference of the Federation of European OR Societies held every two out of three years, the triennial conference of the International Federation of OR Societies.

For more information the reader may refer to Roger A. Forder, "Operational Research in the UK Ministry of Defence: An Overview," in Journal of the Operational Research Society 55 (2004): 319-332. 